\author{
アカデミック・ディテーリングの実践例 \\ 〜基礎薬学とエビデンスに基づく処方支援〜 \\ 佐 藤 将 嗣, *平田淳, 柴原由季

\section{Practice Examples of Academic Detailing -Prescription Support Based on Basic Pharmaceutical Science and Evidence} \\ Masatsugu Sato, ${ }^{*}$ Jun Hirata and Yuki Shibahara \\ Tsujinaka Hospital Kashiwa-no-ha Pharmacy; 148-6 Kashiwanoha Campus, \\ 178-2 Wakashiba, Kashiwa, Chiba 277-0871, Japan.
}

(Received January 10, 2019)

\begin{abstract}
Better prescription assistance can be provided by applying basic pharmaceutical science concepts, and by considering evidence from clinical trials. For example, several drugs are currently used to treat ulcerative colitis (UC), a form of inflammatory bowel disease. In general, after a drug is administered, it is first absorbed into the upper part of the small intestine and then enters the bloodstream. However, 5-aminosalicylic acid (5-ASA), which is commonly used to treat $\mathrm{UC}$, acts locally on the colonic mucosa; its absorption must be prevented in the upper gastrointestinal tract so that it can be delivered to the colorectal mucosa. Therefore, in this case, it is important to consider drug dissolution tests rather than pharmacokinetics. Currently, three types of 5-ASA formulations are available: a pH-dependent release formulation, a time-dependent release formulation, and a combination of the two at maximum dosages of 3600,4000 , and 4800 $\mathrm{mg}$, respectively. Although it is often thought that selecting a high dose is better, the clinical effectiveness of 5-ASA is determined by the amount of drug actually delivered to the lesion. Therefore, rather than dosage, it is most important to understand differences in drug solubility. It is beneficial to provide prescription assistance for the treatment of UC by 5-ASA, because when 5-ASA fails, a steroid or expensive biological drug is administered. We will present a case study and discuss the future of prescription assistance using Academic Detailing.
\end{abstract}

Key words__ academic detailing; inflammatory bowel disease; ulcerative colitis; 5-aminosalicylic acid

\section{1. 日本の診療における問題点}

適切な薬物治療を行う上で, 診療ガイドラインや 治療指針はより簡便で有益な情報源となる。しかし ながら，日本の診療ガイドラインの多くで薬物治療 において明確な選択肢が示されておらず，結果とし て，適切な医薬品の選択に苦慮する事例をしばしば 経験する。わが国における潰瘍性大腸炎（ulcerative colitis; UC）治療についても治療指針1)を確認 すると同様の傾向にあり，初期治療では 5-アミノ サリチル酸（5-aminosalicylic acid; 5-ASA）製剂を 用いるべきところまでは理解できるが, 市販されて いる 5-ASA 製剤のうちの何を選択するべきかにつ

辻仲病院柏の葉診療技術部薬剤科（广277-0871 千葉県 柏市若柴 178 番地 2 柏の葉キャンパス 148 街区 6)

*e-mail: msato@gpro.com

本総説は, 日本薬学会第 138 年会シンポジウムS51 で

発表した内容を中心に記述したものである.
いては明言されていない（Fig. 1)。そのため，薬 剂師が処方支援を行うためには有効性エビデンスを 踏まえ, 医薬品を科学的に比較して使い分けポイン トを示す academic detailing (AD) が有用である. $\mathrm{AD}$ を行うためには，診療ガイドラインや治療指針 のみならず，病態と薬理作用機序を熟知し，各製剤 の製剂的特徵である物理化学的特性と臨床試験の結 果を踏まえた上で吟味し, 評価する必要がある。

\section{2. 病態の理解}

UC は年々増加傾向にあり，わが国においては 20 万人を超える疾患で，その多くが軽症患者であると 言われている. UC を理解する上で重要なことは, 重症度と炎症部位による分類であり, 重症度によつ て, 軽症, 中等症, 重症と分けられ，炎症部位に よって, 直腸炎型, 左側大腸炎型, 全大腸炎型の 3 つに分けられる (Fig. 2). ${ }^{2)} こ の$ 分類は後述する 5-ASA 製剤の分布と有効性を考える上で重要とな 


\section{Introduction of remission (treatment of active ulcerative colitis)}

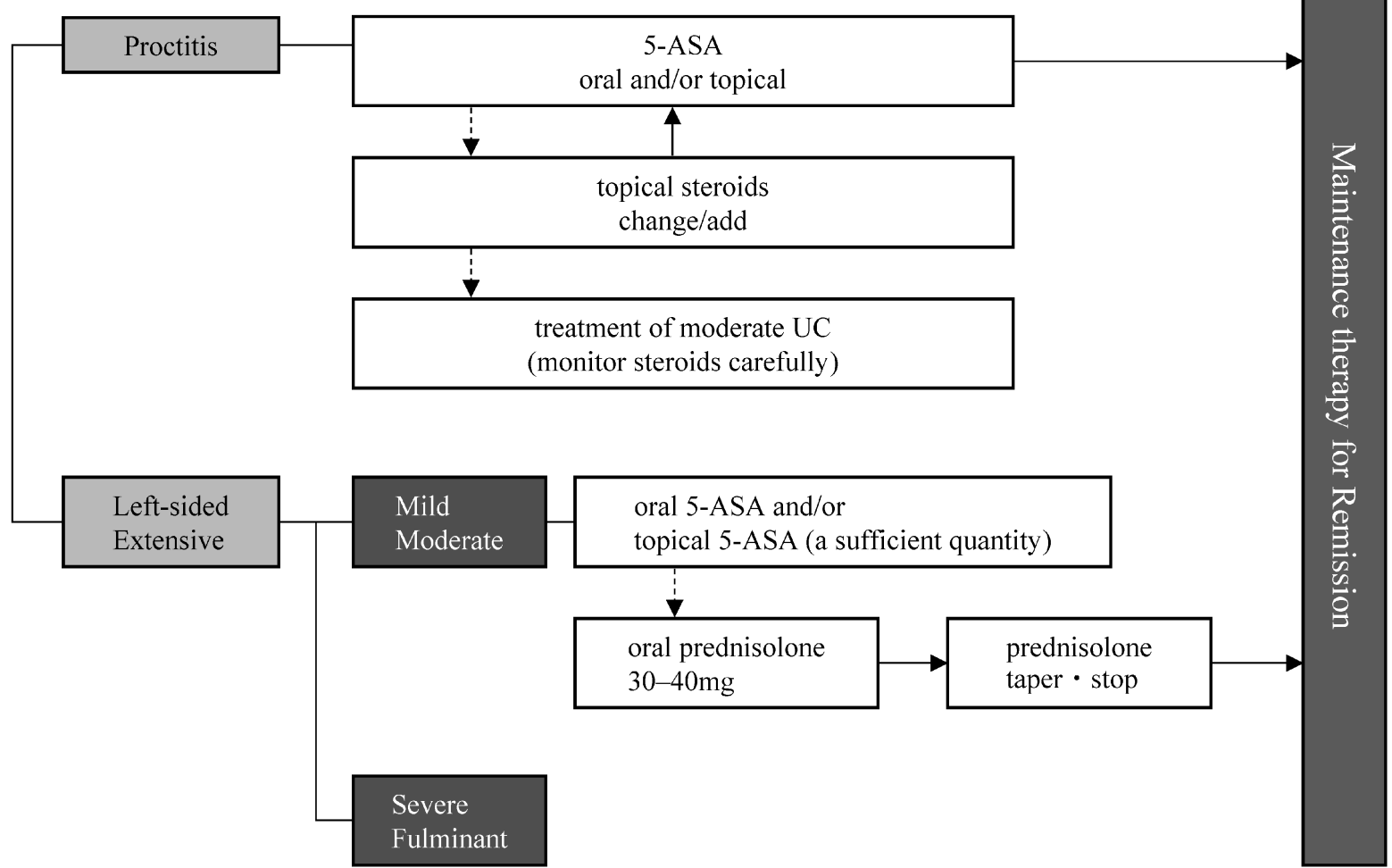

Fig. 1. Standard Treatment Guidelines for Ulcerative Colitis (UC) in Japan The treatment for severe and fulminant UC has been omitted from this figure. Modified from Ref. 1).

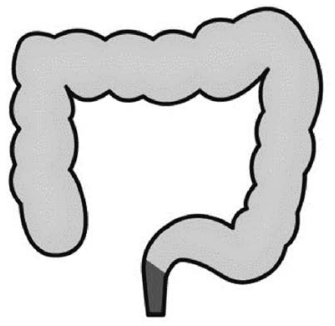

Proctitis

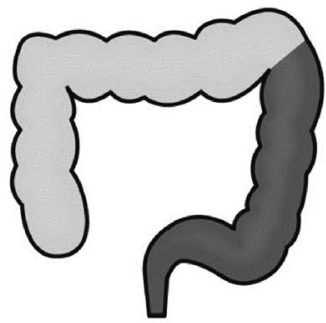

Left-sided colitis

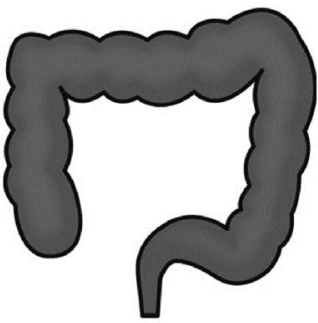

Extensive colitis

Fig. 2. Distribution of UC

The dark gray regions show the areas of inflammation. Based on Ref. 2).

る.

\section{Key drug である 5-ASA 製剤}

従来, UC 治療にはサラゾスルファピリジン (salazosulfapyridine; SASP) が用いられてきた。 SASP は腸内細菌によりアゾ結合が切断され， 5-ASA が生じる（Fig. 3).

この 5-ASA は活性本体であることがわかってお り，同時に生成するスルファピリジンは血中濃度と 有害事象に相関が認められ, ${ }^{3)}$ 副作用の原因である と言われる。そこで 5-ASA 自体を投与すればより
安全ということになる。5-ASA は局所粘膜で作用 することが示されているが, ${ }^{4)}$ 5-ASA を経口投与し たとき，通常，上部消化管においてほとんどが吸収 されてしまい, 病変部である大腸部へは到達しない. よって，何も工夫せず経口投与した場合は効果を発 揮しないため，上部消化管での吸収を抑え，大腸に 到達させる製剤学的な工夫が必要であり，ドラッ グ・デリバリー・システム（drug delivery system; DDS）が重要となる.

わが国で利用可能な経口 5-ASA は pH 依存型製 


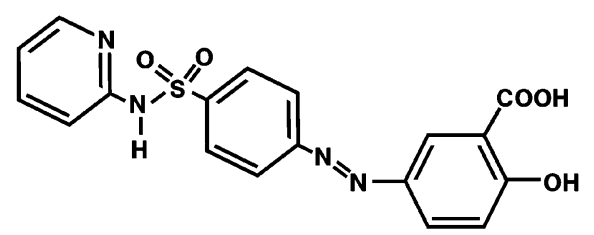

Salazosulfapyridine

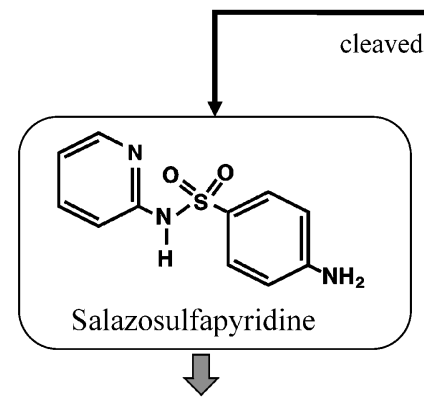

Causes side effects

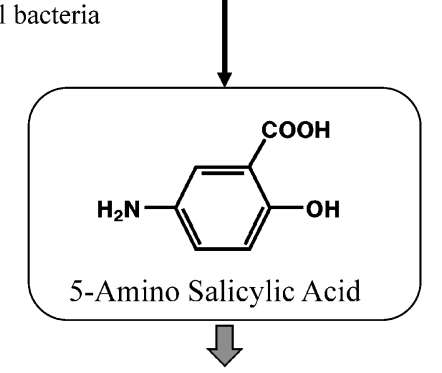

Active moiety

Fig. 3. 5-Aminosalicylic Acid (5-ASA) Is Produced from Salazosulfapyridine

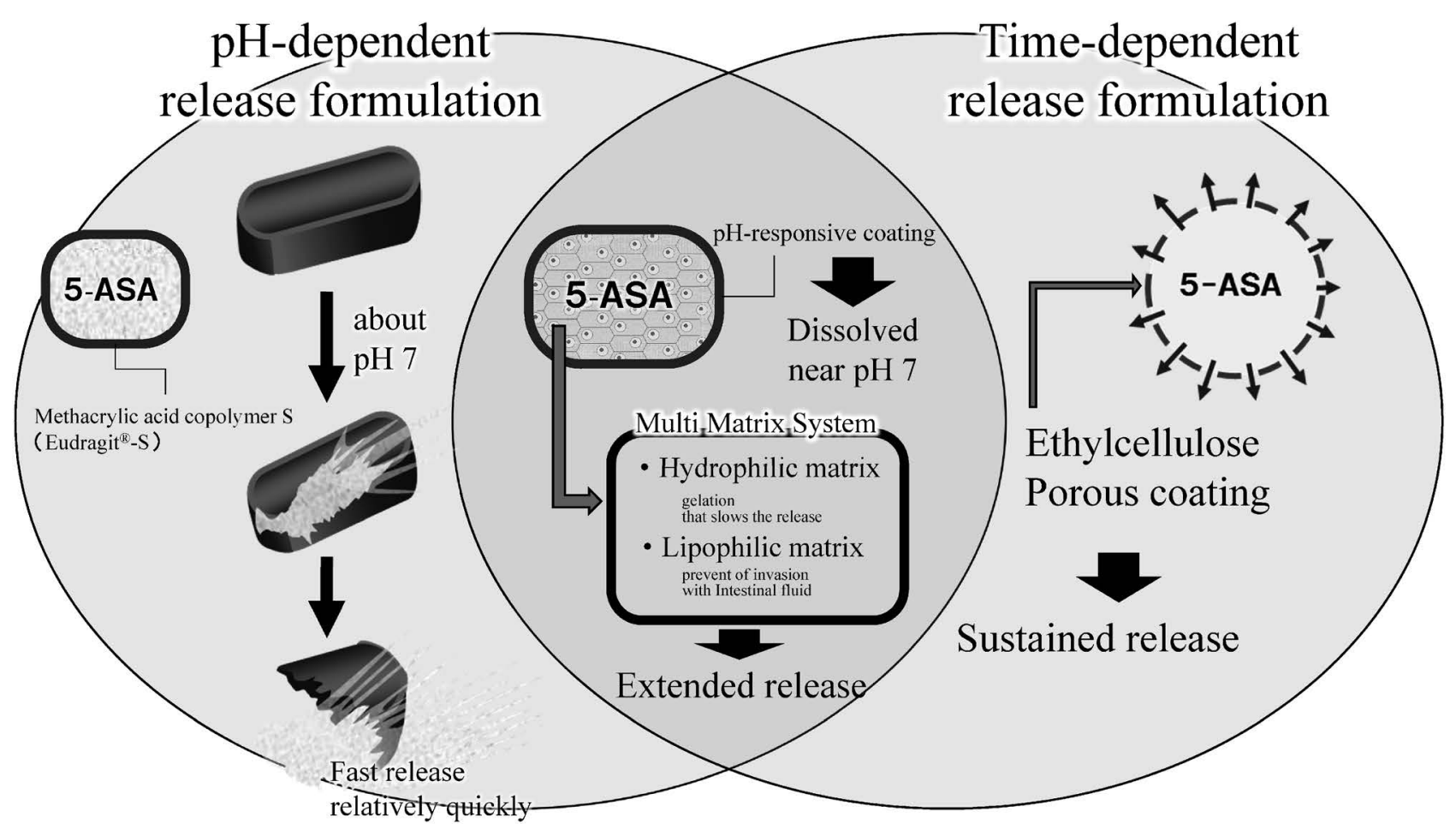

Fig. 4. Three Types of Oral 5-ASA Formulations Are Available in Japan

剂と時間放出型製剂，その 2 つを組み合わせた製剤 の 3 つとなる (Fig. 4). 加えて, 経肛門的に投与 可能な局所製剂が存在する。各 DDS 製剂は, 5-ASA として投与できる最大量は製剤によって 3.6-4.8 g と幅がある. 新しく発売されたものや高 用量を選択するのがよいと思われがちだが，最も重 要なのは病変部における薬剤の到達量であり, その
ため各製剤の溶出性の違いを理解することが極めて 重要となる。そこで各製凨の溶出試験5-7) や報告8) か ら，経口製剂における大腸内の 5-ASA 分布のイ メージを Fig. 5 に示す。 大腸内は複雑な因子が多 くあり，個人差も大きいため，かならずしもこのイ メージ通りになるとは言えないが，このイメージは 医薬品の選択をする上で役に立つ. 


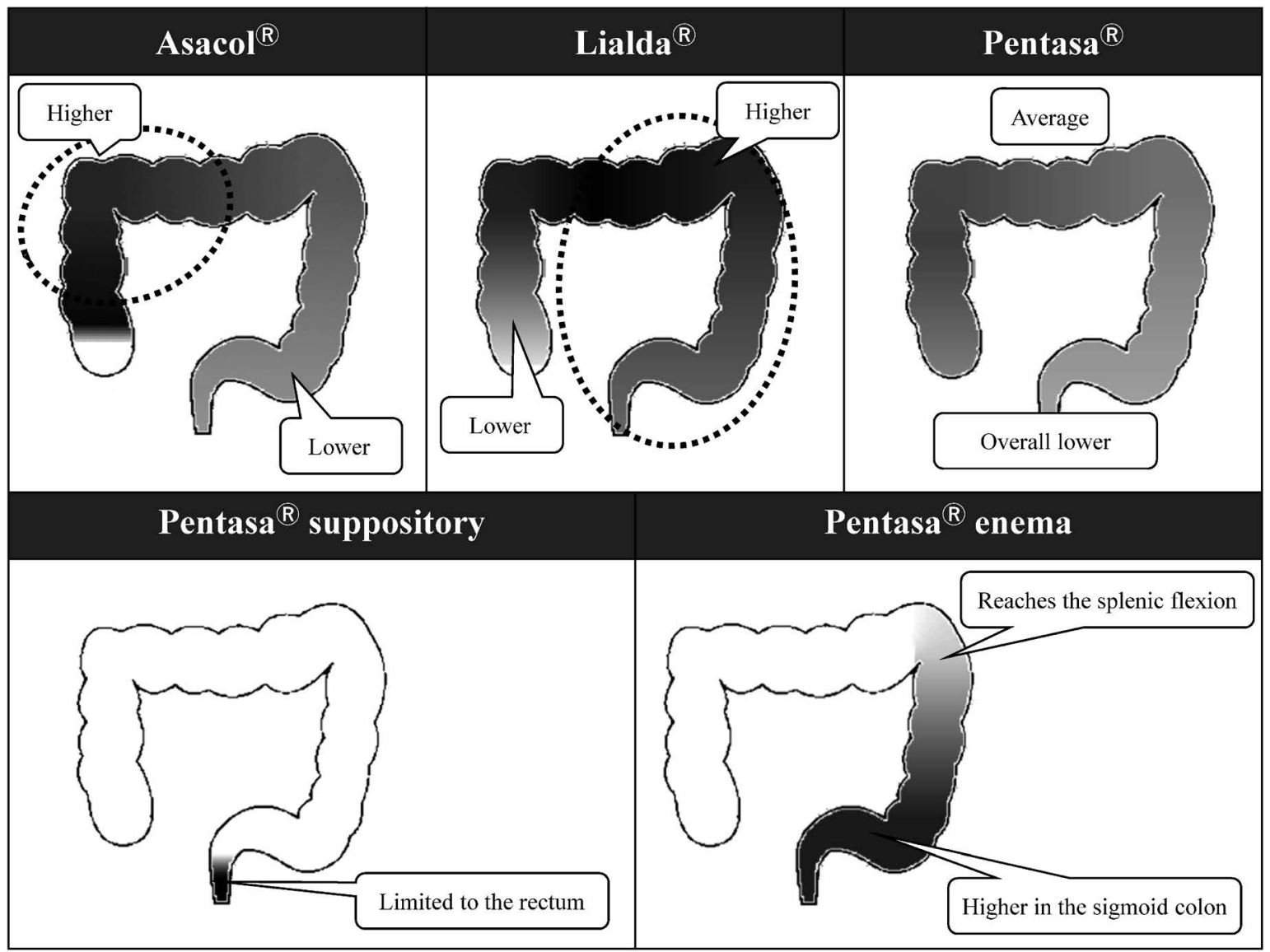

Fig. 5. Simulation of 5-ASA Distribution of 5-ASA Formulations in the Colon The gray regions show 5-ASA distribution. The deeper the contrast, the higher the concentration.

まずアサコールだが $\mathrm{pH}$ 依存型であるため上部 消化管における吸収は完全に免れ，外側の被膜が上 行結腸部にて溶解し，比較的速やかに完全崩壊す る。一気に放出した 5-ASA は肛門側へ流れていく が，5-ASA は大腸においても一部吸収され，加え て粘膜において代謝を受けアセチル化されるの で, ${ }^{9)}$ 徐々に消失し，肛門側に行くに従って濃度は 薄くなると考えられる。よつて右側結腸で濃い分布 となり，左側では薄くなる，次にリアルダ®だが， $\mathrm{pH}$ 依存型の被膜を持つため上部消化管における吸 収はアサコール®同様ほぼないと想定される．被膜 の溶解は，薬物シンチグラフィー・パイロット試験 結果7)からアサコール ${ }^{\circledR} よ り$ 早く起こることがわ かっているが [崩壊開始時間（h）アサコール®: $6.16 \pm 1.80$, リアルダ® $: 4.75 \pm 1.31], 5-A S A$ はマ ルチマトリックスにより放出が高度に制限されてい るため，上行結腸部においては放出が少ない。溶出 試験データから考えると横行結腸付近で 5-ASA 濃 度がより高くなり，徐放性を有しているため比較的
肛門側へも高い濃度を維持すると考えられる．した がって，右側結腸では比較的薄く，左側結腸で濃い 濃度分布になると考えられる。最後にペンタサ ${ }^{\circledR}$ は，時間放出型製剤であり，時間とともに放出する ため，上部消化管で溶出した 5-ASA は吸収され， 吸収を免れた 5-ASA とまだ溶出していない 5-ASA が大腸へ到達する，その後は時間とともに5-ASA を放出するため，右側〜左側にかけて平均的な分布 になるが，上部消化管での吸収による損失を考慮す ると，他 2 剂に比べて全体的に 5-ASA はやや薄い 濃度分布になると考えられる。

局所製剤は，ペンタサ ${ }^{\circledR}$ 坐剂とペンタサ®注腸が あるが，ペンタサ®坐剂の 5-ASA が到達する部位 は直腸部に限局され，S 状結腸より口側へは分布し ない. ${ }^{10)}$ ペンタサ® 注腸では, 5-ASA は脾彎曲部ま では到達し，それより口側には分布しないことがわ かっている. ${ }^{11)}$

5-ASA が局所粘膜で作用することを考えると， 病変部位と 5-ASA 分布が一致するほど，より効果 


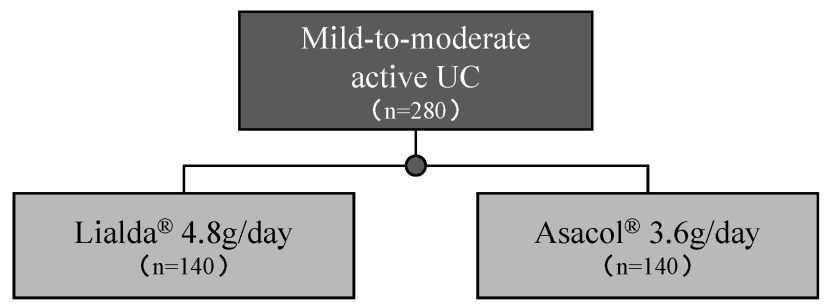

A)

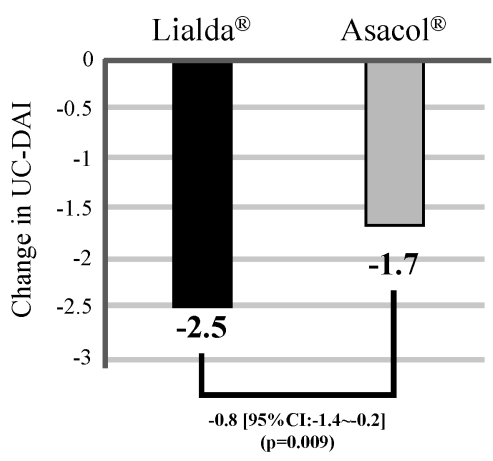

B)

Proctitis

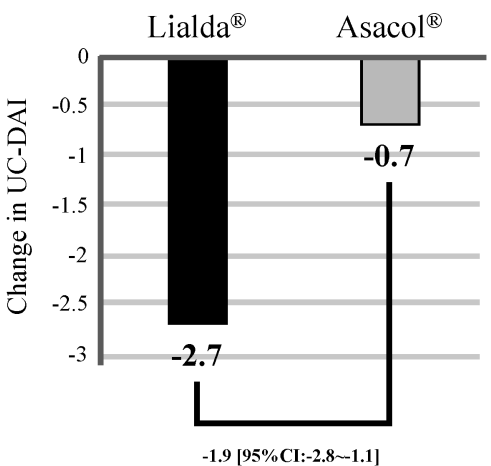

$\underline{\text { No Proctitis }}$

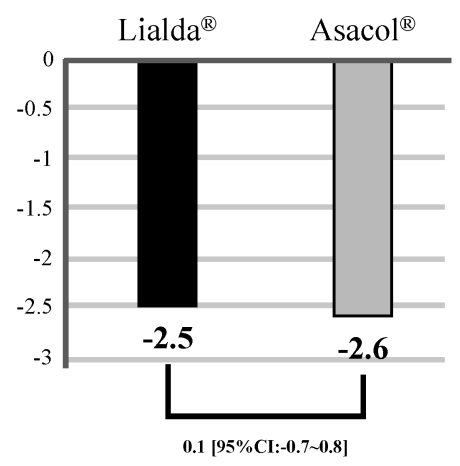

Fig. 6. Clinical Trial of Lialda ${ }^{\circledR}$ Was Conducted to Evaluate Its Noninferiority and Superiority Compared to Asacol ${ }^{\circledR}$

The study evaluated the noninferiority, as determined by the change in UC-disease activity index (UCDAI) as the primary endpoint. When noninferiority was met, superiority continued to be evaluated. Figure was created based on Ref. 7). A) Results of superiority trial under the condition that noninferiority was met. In the result, the difference in UCDAI among the treatment groups was statistically significant for Lialda ${ }^{\circledR}$. B) Results of the subanalysis. In the case of proctitis, this difference was more remarkable. However, with the exception of proctitis, the advantage of Lialda ${ }^{\circledR}$ disappeared and Asacol ${ }^{\circledR}$ was slightly favorable.

的であることが考察できる．また，腸内環境を考え たとき，腸管運動が制限される場合（糖尿病や抗コ リン作用を持つ薬剤の服用など） はこの分布がより 右側にシフトし，下痢など腸管移動速度が上昇する 場合は左側にシフトすることが考えられる，以上よ り，患者の基礎疾患や併用薬などの患者背景を踏ま えたうえで，各 5-ASA 製剤の製剤学的特徵を考慮 した医薬品の選択が重要となる。

\section{4. 臨床試験}

Figure 6 にリアルダ®の治験結果とサブグループ 解析結果を示す.

リアルダ®のアサコール视に対する非劣性検証 後, リアルダ®の優越性を確認する試験であり，主 要評価項目は Ulcerative Colitis Disease Activity In$\operatorname{dex}(\mathrm{UC}-\mathrm{DAI})$ スコアの投与期開始時からの変化量 を比較したもので, リアルダ®の優越性が確認され ている [アサコール®に対する群間差：-0.8(95\% CI : - 1.4〜 - 0.2) $(p=0.009)]$. サブグルーブ解 析で見てみると, 直腸炎型では, この差がより顕著 となる [アサコール ${ }^{\circledR} に$ 対する群間差 ：-1.9(95\% CI : $-2.8 \sim-1.1)]$ 。これはリアルダ®の放出特性 である左側結腸でより 5-ASA 濃度が濃くなる特徵
を示しており，上行結腸で一気に崩壊するアサコー ル ${ }^{\circledR}$ は左側結腸での濃度がリアルダ®よりも薄くな るためだと考えられる。

一方，直腸炎型以外だと優越性はみられなくな り，極めてわずかながらだがアサコール のほうが よいような結果 [アサコール®に対する群間差 : 0.1 (95\% CI ：-0.7〜0.8) ] となる.これはアサコー ル ${ }^{\circledR}$ の溶出が上行結腸で起こり，高濃度に放出する ことでリアルダ®よりも左側結腸からより広範囲で 5-ASA が広がることに起因するものと考えられ る.上記のように, 病変部位と 5-ASA 分布の特徵 が有効性に強く関係していることが示唆される。一 方，炎症部位により直接的に作用させる局所製剂は 非常に有効な手段であり，実際に局所製剂の有用性 は報告されている. ${ }^{12,13)}$ また, アドヒアランスも有 効性に関連している14)ことも考慮する必要がある.

\section{5. 潰瘍性大腸炎治療の AD ツール}

$\mathrm{AD}$ は使い分けポイントを示す適切なツールが重 要となる．詳細はここでは述べないが，ツールの一 部である科学的視点から考えた新たなフローチャー 卜案を Fig. 7 に示す.

対象となる患者は，患者数が多い軽症〜中等症と 


\section{Introduction of remission (treatment of Active Ulcerative Colitis)}

\section{Proctitis}

Lialda ${ }^{\circledR} 4.8 \mathrm{~g}+$ Pentasa $^{\circledR}$ supp. $1 \mathrm{~g}$

※ Strongly consider topical formulations!

\section{Left-sided or Extensive}

Pentasa $^{\circledR} 4 \mathrm{~g}$ or Asacol $^{\circledR} 3.6 \mathrm{~g} \pm$ Pentasa $^{\circledR}$ enema $1 \mathrm{~g}$

※ The enema formulations should be used, depending on the inflammatory condition. The suppository can also be selected.

option

Lialda $^{\circledR} 4.8 \mathrm{~g}$ can be selected, considering adherence.

※ 5-ASA should be used at as high a dose as possible
Treatment

failure

Confirm the following;

- Prescription of topical formulation

- Adherence

- Intestinal motility and the environment

Try rotation of oral 5-ASAs

Introduction of steroids

※ Consulting a specialist is desirable
Maintenance therapy for Remission

Consider the following choices depending on the cause of non-adherence.

- The patient missed a dose or was busy

Select more simple dosing (preferably once daily)

- Swallowing problems

Select a granular formulation or take less tablets at an

equivalent dose

Fig. 7. Flowchart of Initial Therapy for Mild or Moderate UC by Applying Basic Pharmaceutical Science Concepts and Considering Evidence from Clinical Trials

Severe and fulminant UC have been omitted from this flowchart, because a specialist should be consulted for those conditions. For moderate UC, some patients may need more potent treatment like that used for severe and fulminant UC. A rotation of oral 5-ASAs is acceptable, but it is most important that a topical formulation be prescribed, especially for proctitis.

し，炎症部位によって選択すべき医薬品を評価し た。まず直腸炎型だが，炎症部位を考えると坐剤を 選択することが最も適切である。経口製剤であれ ば，より肛門側へ送達可能なリアルダ®が第一選択 になる．次に左側大腸炎型と全大腸炎型だが，経口 製剤はより広範囲に分布するペンタサ®かアサコー ル 選択する．臨床試験の結果を考慮すればリア ルダ®も利用可能であり，1日 1 回服用であること を考えると，患者のアドヒアランスに応じて選択す るのが妥当であると考えられる。国内の臨床試 験5-7)の結果より，左側大腸炎型と全大腸炎型では 5-ASA の投与量をできる限り高用量で用いた方が より有効であることが示唆されたことから，最大投 与量とする，局所製剤は坐剂より，より広範囲に分 布する注腸を選択する。それでもうまくいかない場 合にはステロイドの使用など次の治療を考慮する. 中等症の中にはより強力な治療を要する患者がいる ことに留意すべきだが，軽症〜中等症の多くの患者
がこのフローチャートで治療可能であると考えてい る.

今後, 各疾患において薬剤師が $\mathrm{AD}$ ッールを作 成し，医師への処方支援を行うことで患者の最適処 方に貢献することが重要であるが，ツール作成に際 しては，大学等の基礎系教員や臨床系教員との連携 が欠かせないと考えている。

\section{6. 症例提示}

30 歳代，女性，排便時出血にて来院し，内視鏡 検査にて潰瘍性大腸炎と診断され，アサコールが 開始となり, 病状はコントロールされた. その後, 出血は時々みられるものの改善傾向を示していた. 1 年後, 内視鏡検査にて直腸病変が 1 年前とあまり 変化していないことがわかり, 薬剤師にステロイド 導入について相談があった.

本症例は直腸炎が改善していないため，経口 5-ASA が遠位大腸まで到達していない，又は不足 していると考え，主治医に潰瘍性大腸炎治療の $\mathrm{AD}$ 
ツールを使用し， $\mathrm{AD}$ を行い，経口 5-ASA 製剤は より遠位に到達するリアルダ®への切り替えと, 局 所製剂であるペンタサ ${ }^{\circledR}$ 坐剤を追加することを提案 した。 その結果, まずは, ペンタサ坐剂のみが, 追加処方となったが, 経過は良好となり, 1 年後, 内視鏡検査にて粘膜に炎症所見はみられず，病理検 査でも寬解の判定となった。

本症例は医薬品の選択ポイントを示す潰瘍性大腸 炎治療の $\mathrm{AD}$ を行うことで, 処方が変更になり, 患者の治療に貢献できたと考える.

\section{7. まとめ}

潰瘍性大腸炎患者は増加傾向にあるため, 専門医 以外でも診ることが多くなることが予想される，そ の際，薬剂師が 5-ASA 製剂の使い分けポイントを わかり易く示す $\mathrm{AD}$ を行うことで，患者にとって 最適な医薬品が選択され, 医療経済上の効果にもつ ながる可能性がある。 AD を普及させるためには, 医薬品の特性を科学的に理解できる薬剤師の知識と 技能が必要である。今回提示した症例は問い合わせ を受けた後の行動だが, 今後は薬剂師が能動的に新 薬が発売されたタイミングなどで， $\mathrm{AD}$ を行い，処 方行動に影響を与え, 薬物治療の最適化につなげて いく必要がある.

\section{利益相反＼cjkstart開示すべき利益相反はない．}

\section{REFERENCES}

1) Suzuki Y., Clinical Practice Guidelines for the diagnosis and treatment of Ulcerative colitis and Crohn's disease, The Separate volume of the Study report at H28 by Grants-in-Aid for Scientific Research. Ministry of Health, Labour and Welfare, Japan, 2017.

2) Health and Labour Science Research Grants from the Ministry of Health and Welfare of Japan, and Research on Measures for Intractable Disease, "Hitomede wakaru IBD," 2nd ed., 2015.
3) Khan A. A., Howes D. T., Piris J., Truelove S. C., Gut, 21, 232-240 (1980).

4) Frieri G., Giacomelli R., Pimpo M., Palumbo G., Passacantando A., Pantaleoni G., Caprilli R., Gut, 47, 410-414 (2000).

5) Asacol $^{\circledR}$ tablets $400 \mathrm{mg}$ Interview form, 8th ed., ZERIA Pharmaceutical Co., Ltd., 2017: 〈http://www.info.pmda.go.jp/go/interview/ 2/380077_2399009F3028_2_010_1F.pdf $\rangle$, cited 14 April, 2019.

6) PENTASA $^{\circledR}$ Tablets $250 \mathrm{mg}, 500 \mathrm{mg}$, and Granules 94\%, Interview form, 20th ed., KYORIN Pharmaceutical Co., Ltd., 2017: 〈http://www.info.pmda.go.jp/go/interview/ 1/230109_2399009F1149_1_022_1F.pdf $\rangle$, cited 14 April, 2019.

7) LIALDA $^{\circledR}$ Tab. $1200 \mathrm{mg}$ Interview form, 3rd ed., MOCHIDA Pharmaceutical Co., Ltd., 2017: / http: / / www.info.pmda.go.jp / go / interview/1/790005_2399009F4024_1_M04_ 1F.pdf $\rangle$, cited 14 April, 2019.

8) Abinusawa A., Tenjarla S., Adv. Ther., 32, 477-484 (2015).

9) Bondesen S., Pharmacol. Toxicol., 81, 1-30 (1997).

10) PENTASA ${ }^{\circledR}$ Suppositories $1 \mathrm{~g}$, Interview form, 6th ed., KYORIN Pharmaceutical Co., Ltd., 2017.

11) PENTASA $^{\circledR}$ Enema $1 \mathrm{~g}$ Interview form, 15 th ed., KYORIN Pharmaceutical Co., Ltd., 2017.

12) Ford A. C., Khan K. J., Achkar J. P., Moayyedi P., Am. J. Gastroenterol., 107, 167-176 (2012).

13) Marteau P., Probert C. S., Lindgren S., Gassul M., Tan T. G., Dignass A., Befrits R., Midhagen G., Rademaker J., Foldager M., Gut, 54, 960-965 (2005) .

14) Mitra D., Hodgkins P., Yen L., Davis K. L., Cohen R. D., BMC Gastroenterol., 12, 132 (2012). 